\title{
Impact of the amount of working fluid in loop heat pipe to remove waste heat from electronic component
}

\author{
Martin Smitka ${ }^{1, a}$, Z. Kolková ${ }^{1}$, Patrik Nemec ${ }^{1}$ and M. Malcho ${ }^{1}$ \\ ${ }^{1}$ University of Žilina, Departure of Power Engineering, Univerzitna 1, 01026 Žilina, Slovakia
}

\begin{abstract}
One of the options on how to remove waste heat from electronic components is using loop heat pipe. The loop heat pipe (LHP) is a two-phase device with high effective thermal conductivity that utilizes change phase to transport heat. It was invented in Russia in the early 1980's. The main parts of LHP are an evaporator, a condenser, a compensation chamber and a vapor and liquid lines. Only the evaporator and part of the compensation chamber are equipped with a wick structure. Inside loop heat pipe is working fluid. As a working fluid can be used distilled water, acetone, ammonia, methanol etc. Amount of filling is important for the operation and performance of LHP. This work deals with the design of loop heat pipe and impact of filling ratio of working fluid to remove waste heat from insulated gate bipolar transistor (IGBT).
\end{abstract}

\section{Introduction}

The trend development of electronic components is miniaturization of the dimension. It leads to an increase waste heat. This heat often leads to lower performance and failure of electronic components in case of insufficient cooling. In order to maintain appropriate working conditions, waste heat must be removed. In many cases, an air fin cooler with natural or forced convection is used to removing waste heat. We have also other possibilities to remove waste heat. One of possibility to remove waste heat is use loop heat pipe (LHP).

LHPs are two-phase heat transfer devices that utilize the evaporation and condensation of a working fluid to remove heat, and the capillary forces developed in fine porous wicks to circulate the fluid. It was developed in 1972 by Gerashimov and Maydanik of the Ural Polytechnic Institute. LHP consists of an evaporator with wick, a condenser, a compensation chamber, and liquid and vapor line (Figure 1). Only the evaporator and the compensation contain wicks; the rest of the loop is made of smooth wall tubing. The wick in the evaporator is made with fine pores for purpose of developing a capillary pressure to circulate fluid around the loop, while the wick in the compensation chamber is made with larger pores for purpose of managing fluid ingress and egress. The operating principle of the LHP is as follows. As heat is applied to the evaporator, liquid is vaporized and the menisci formed at the liquid/vapour interface in the evaporator wick develop capillary forces to push the vapour through the vapour line to the condenser. Vapour condenses in the condenser and the capillary forces

\footnotetext{
a martin.smitka@fstroj.uniza.sk
}

continue to push liquid back to the evaporator. The waste heat from the heat source provides the driving force for the circulation of the working fluid and no external pumping power is required. The two - phase compensation chamber stores excess liquid and controls the operating temperature of the loop. [1]

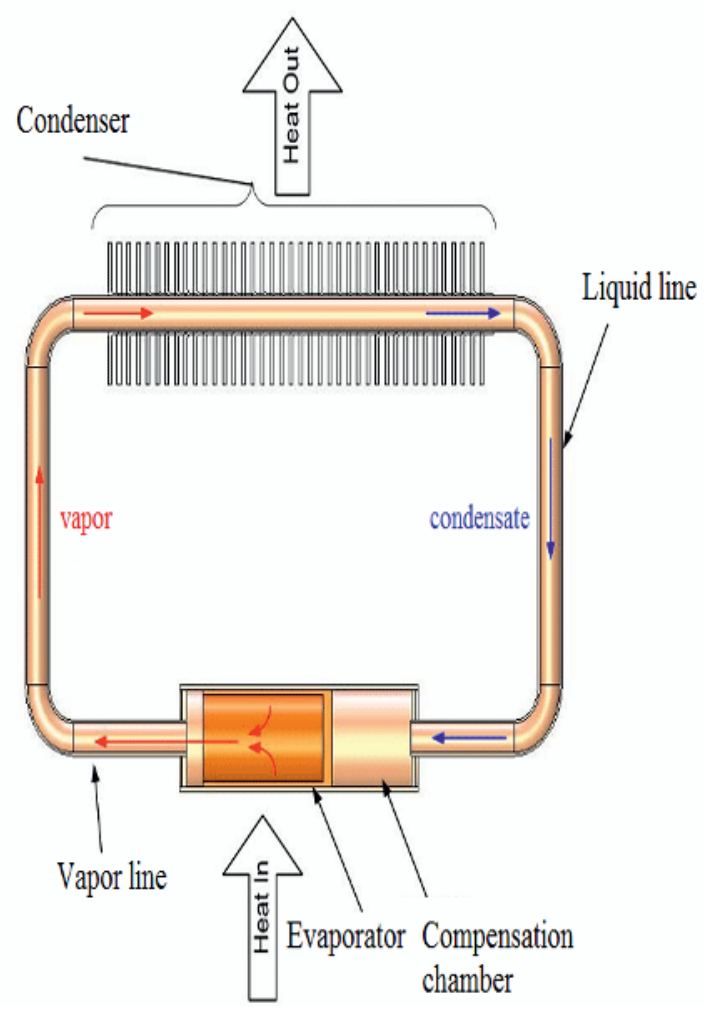

Figure 1. Schematic diagram of LHP. [2] 


\section{Material and working fluid of LHP}

The main structural material for making elements of the LHP body is stainless steel, which is amenable to different kinds of vacuum-hermetic welding and possesses a sufficiently high strength. Disadvantage of stainless steel is its relatively low thermal conductivity. Copper is also quite a suitable material for use in LHPs [3].

Sintered nickel powder is most widely distributed as wick structure. It is possible to obtain capillary structures with quite a small pore size, possess a high strength and it is compatible with many low-temperature working fluids. There are also successful examples of using cheaper polymeric, ceramic, copper and stainless steel porous materials.

The choice of working fluids for LHPs is realized on the basis of the same criteria as for conventional heat pipes. The most efficient working fluid for LHPs in the temperature range from $-20{ }^{\circ} \mathrm{C}$ to $+150{ }^{\circ} \mathrm{C}$ is ammonia and water. The advantages of water manifest themselves at higher temperatures and reach the maximum at 100$150^{\circ} \mathrm{C}$. When the working fluid is water, one should bear in mind that freezing is impermissible because of the danger of disturbing the device tightness. Neon, oxygen, nitrogen, ethane, propane, propylene, freon 152A, freon $11, n$-pentane, acetone and toluene were also successfully used as working fluids for LHPs [3].

\section{Effect of fluid charge}

The compensation chamber volume Vcc must be able to accommodate at least the liquid volume swing (and density changes) between the hot case and the cold case of the loop operation [4]. The fluid inventory must satisfy the following relationships for the cold and the hot cases, respectively:

$$
\begin{aligned}
& M=\rho_{l, c}\left[V_{l}+V_{p w}+V_{s w}+V_{g r o o v e}+V_{v+}\right. \\
& \left.+V_{c o n d}+(1-\beta) V_{c c}\right]+\rho_{v, c} \beta V_{c c} \\
& M=\rho_{l, h}\left[V_{l}+V_{p w}+V_{s w}+(1-\alpha) V_{c c}\right]+ \\
& +\rho_{v, h}\left[V_{\text {groove }}+V_{v}+V_{c o n d}+\alpha V_{c c}\right],
\end{aligned}
$$

where $V_{l}$ is the volume of the liquid line; $V_{p w}$ and $V_{s w}$ are the void volumes of the primary wick and secondary wick, respectively; $V_{\text {groove }}, V_{v}$, and $V_{\text {cond }}$ are the volumes of the evaporator grooves, the vapour line and the condenser, respectively. $\beta$ and $\alpha$ correspond to the void fraction of the fluid in the compensation chamber at the cold and hot cases, respectively. $\beta$ and $\alpha$ are selected at the designer's discretion. Once these values are determined, the compensation chamber volume and the fluid inventory can be calculated from the above equations. At any operating mode of the LHP, both liquid and vapour phases have to coexist in the compensation chamber. Then, it is meaningful to study the fluid charge effect on the LHP performance as long as the compensation chamber is filled with a two-phase fluid. [5]

\section{Design of LHP}

Before LHP was constructed, the design of it was made in CAD-program. As constructional materials for LHP were selected cooper and cooper pipes. Model of LHP is shown in the figure 2 . When the loop heat pipe was constructed, it was vacuumed and filled with a working fluid. As the working fluid was used distilled water.

Inside the evaporator was located wick structure of sintered copper powder. There was cooper powder with grain size $50 \mu \mathrm{m}$ and it was sintered at temperature 950 ${ }^{\circ} \mathrm{C}$ for 30 minutes. This type of wick was selected based on previous measurements.

To avoid heat loss (it is also called "heat leak") into the compensation chamber was inserted a brass flange with rubber seal between the evaporator and the compensation chamber. It was attached using bolts. The rubber seal was approximately $15 \mathrm{~mm}$ thick and both sides were lubricated with vacuum paste to ensure better tightness.

On the evaporator was mounted the aluminum block, and on the aluminum block was fixed Insulated gate bipolar transistor (IGBT). IGBT was connected to power source and transistor was loaded by DC. The maximum permissible temperature of the IGBT was $100^{\circ} \mathrm{C}$. For better heat transport was applied thermal conductive paste on the connection between the IGBT and aluminum block and between aluminum block and the evaporator. The condenser was made as a tube heat exchanger. The condenser was cooled by cooling water. The temperature of cooling water was set at $20^{\circ} \mathrm{C}$ and it was regulated by a thermostat. The temperatures were measured with the thermocouples. The schematic diagram of measuring device can be observed in the figure 3 .

Tab.1 Main design parameters of the LHP

\begin{tabular}{|l|l|}
\hline LHP evaporator & \\
\hline Total length (mm) & 130 \\
\hline Active length (mm) & 89 \\
\hline Outer/inner diameter $(\mathrm{mm})$ & $28 / 26$ \\
\hline Material & copper \\
\hline Saddle & \\
\hline Size (length/ high/ wide) & $118 / 89 / 40$ \\
\hline Material & alumina \\
\hline Sintered copper powder & \\
\hline Number of vapor grooves & 6 \\
\hline Porosity (\%) & 51 \\
\hline Outer/inner diameter $(\mathrm{mm})$ & $26 / 8$ \\
\hline Compensation chamber & \\
\hline Outer/inner diameter $(\mathrm{mm})$ & $35 / 33$ \\
\hline Length (mm) & 110 \\
\hline Charge mass & \\
\hline Distilled water & $40-80 \%$ \\
\hline Vapor line & \\
\hline Length (mm) & 670 \\
\hline Outer/inner diameter $(\mathrm{mm})$ & $6 / 4$ \\
\hline Liquid line & \\
\hline Length (mm) & 820 \\
\hline Outer/inner diameter $(\mathrm{mm})$ & $6 / 4$ \\
\hline
\end{tabular}




\begin{tabular}{|l|l|}
\hline Condenser & \\
\hline Length $(\mathrm{mm})$ & 420 \\
\hline Outer/ inner diameter $(\mathrm{mm})$ & $6 / 4$ \\
\hline
\end{tabular}

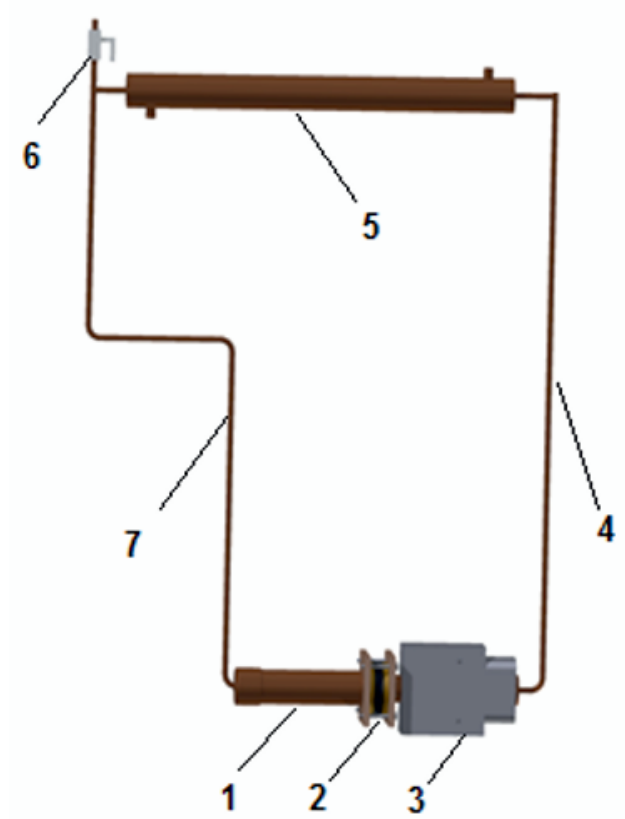

Figure.2. Model of the LHP: 1. compensation chamber, 2. rubber seal, 3. alumina block, 4. vapor line, 5. condenser 6 . filling valve, 7. liquid line.

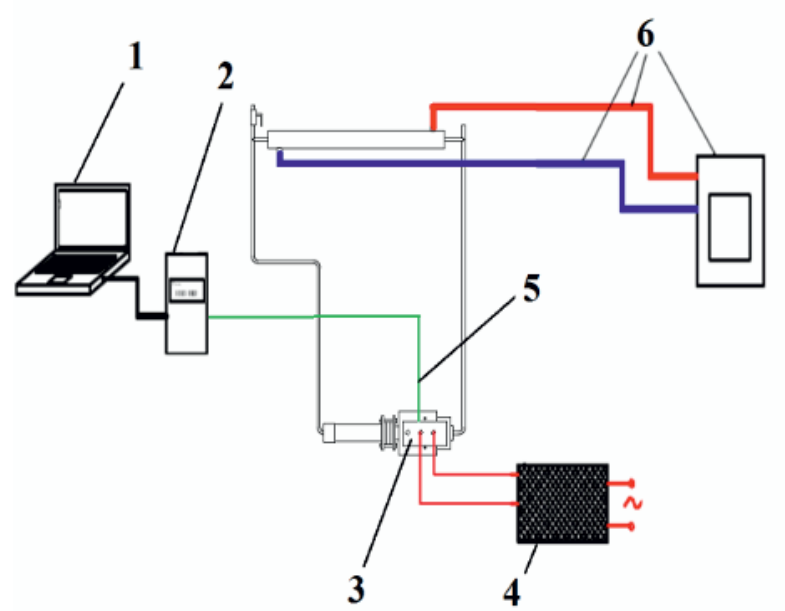

Figure 3. Schematic diagram of measuring device: 1-PC, 2logger, 3-IGBT, 4- power supply voltage and current, 5thermocouple, 6- thermostat.

\section{Results and discussions}

Purpose of this measurement was to determine the impact of filling ratio on cooling performance of the LHP. Recent researches have shown that the ideal amount of filling ratio is about $50-60 \%$.

All measurements were performed in vertical position of LHP. It means, the evaporator was below the condenser and this position is the best for cooling performance of this type of the LHP.
All temperatures were measured with thermocouple and results were evaluated by a computer. The temperature of ambient was $22{ }^{\circ} \mathrm{C}$ and temperature of refrigerant $20^{\circ} \mathrm{C}$.

Inside the LHP was created vacuum before filling it with working fluid. Subsequently, the LHP was filled the required amount of working fluid. The whole volume of the LHP was 162 milliliter.

The first measurement was performed at $40 \%$ of filling ratio $(65 \mathrm{ml})$. The results from the first measurement can be seen in the figure 4 . We can see that temperature of IGBT achieves $100{ }^{\circ} \mathrm{C}$ when it is loads by $200 \mathrm{~W}$.

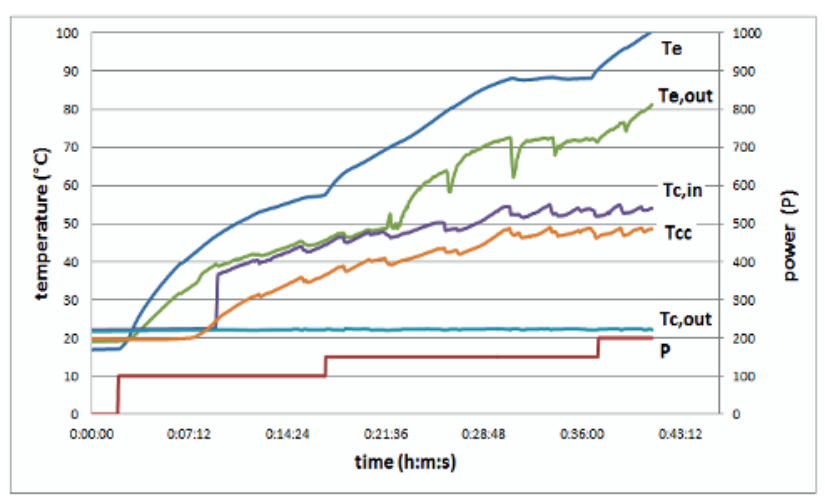

Figure 4. Temperature of working fluid and the IGBT by $40 \%$ of filling ratio.

Te- temperature of the IGBT, Te,out- temperature of working fluid outlet evaporator, Tc,in- temperature of working fluid inlet condenser, Tc,out- temperature of working fluid outlet condenser, Tcc- temperature of working fluid inlet compensation chamber, $\mathbf{P}$ - power of load.

The second measurement was performed at $50 \%$ of filling ratio $(81 \mathrm{ml})$. The results are in the figure 5 . We can see that temperature of the IGBT achieves $100{ }^{\circ} \mathrm{C}$ when it is loads by $250 \mathrm{~W}$.

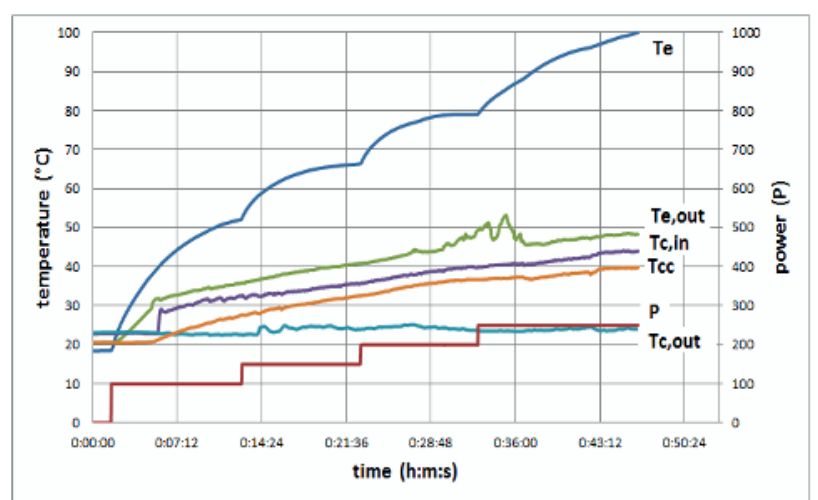

Figure 5. Temperature of working fluid and the IGBT by $50 \%$ of filling ratio.

The third measurement was performed at $60 \%$ of filling ratio $(97 \mathrm{ml})$. The results are in the figure 6 . We can see that temperature of the IGBT achieves $100{ }^{\circ} \mathrm{C}$ when it is loads by $400 \mathrm{~W}$. It can be seen that in this case it is possible to the IGBT loaded more power than in the first and second case. It means that this amount of working fluid is more suitable. It demonstrated good cooling performance of the LHP. 


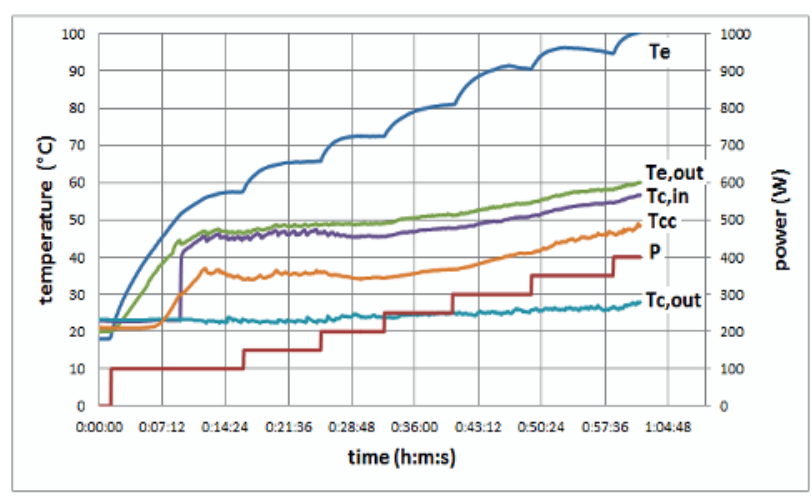

Figure 6. Temperature of working fluid and the IGBT by $60 \%$ of filling ratio.

Next measurement was performed at $70 \%$ of filling ratio $(113 \mathrm{ml})$. In this case, the cooling performance of LHP is very good. It is almost same like with $60 \%$ of filling ratio. The results from this measurement can be seen in the figure 7 . We can see that temperature of the IGBT achieves $100{ }^{\circ} \mathrm{C}$ when it is loads by $450 \mathrm{~W}$. This amount of working fluid is suitable for this type of the LHP.

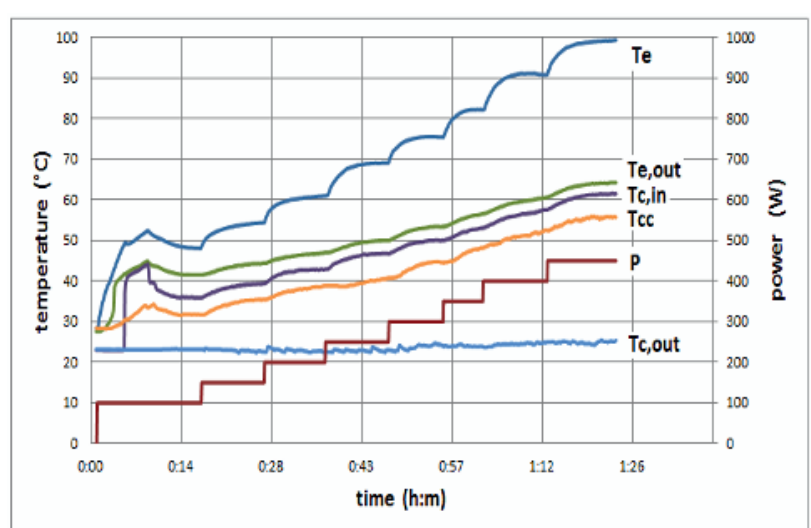

Figure 7. Temperature of working fluid and the IGBT by $70 \%$ of filling ratio.

The last measurement was performed at $80 \%$ of filling ratio $(130 \mathrm{ml})$. The results are in the figure 8 . We can see that temperature of the IGBT achieves $100{ }^{\circ} \mathrm{C}$ when it is loads by $100 \mathrm{~W}$. The cooling performance of the LHP is worse than in the previous cases. It means that this amount of working fluid is not suitable for this type of the LHP.

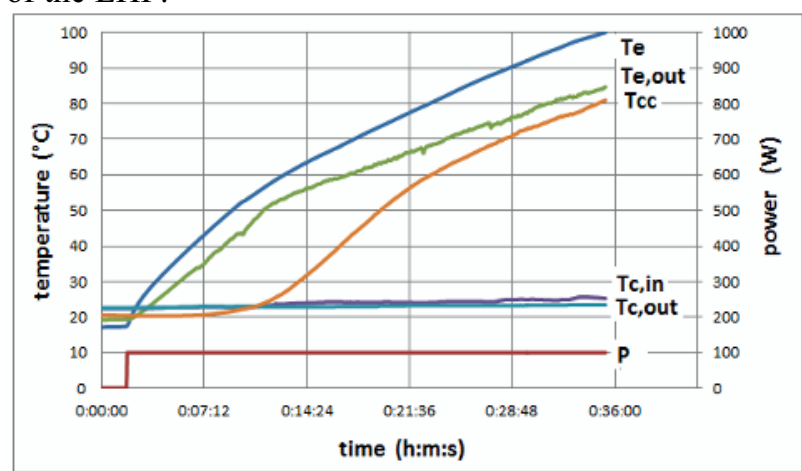

Figure 8. Temperature of working fluid and the IGBT by $80 \%$ of filling ratio.

\section{Conclusions}

The Aim of this work was to develop a loop heat pipe (LHP) for cooling the IGBT and determine the impact of the amount of working fluid in the LHP to remove waste heat from the IGBT. LHP was made of cooper pipes and it was able to remove waste heat from the IGBT. We can also observe that filling ratio has a significant impact on cooling performance of the LHP. When filling ratio was $80 \%$ the LHP stopped working.

From the measurement it can be seen that the best amount of working fluid is between $60-70 \%$ of filling ratio. In this case, IGBT can be loaded by $400 \mathrm{~W}$ and its temperature doesn't exceed $100^{\circ} \mathrm{C}$. It demonstrates good cooling performance of the LHP and it's possible to use in practise. In the figure 9 we can see how filling ratio influences to cooling performance of the LHP.

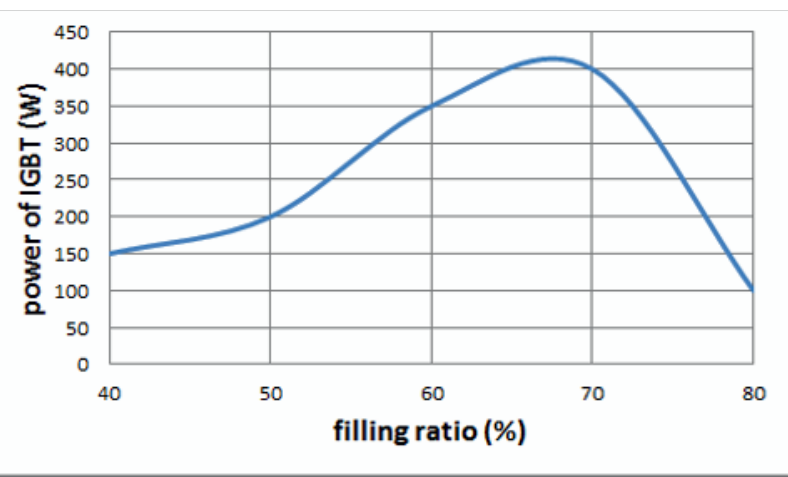

Figure 9. Maximum load of the IGBT at different filling ratio.

\section{Acknowledgement}

This paper was created within the solution of project APVV-0577-10.

\section{References}

1. D. Reay, P. Kew, Heat Pipes-Theory, design and applications, Burlington: Elsevier, (2006)

2. http:// www.1-act.com/advanced-technologies/heatpipes/heat-pipe-loop (2013)

3. Yu. F. Maydanik, Loop heat pipes, in: Applied thermal engineering 25, 635-657, (2005)

4. J. Ku, Operating characteristic of loop heat pipes, in: International conference on environmental system, Denver (1999)

5. S. Launay et al., International Journal of Thermal Sciences 46, 621-636, (2007)

6. J. Andrews, A. Akbarzadeh, I. Saucius, Heat pipe technology: Theory, applications and prospect, Melborne: Pergamon (1996)

7. P. Nemec, M. Malcho, M. Smitka, J. Matušov, Performance parameters of closed loop thermosyphon, volume 14, 53-57, (2012)

8. M. Kasanický, M. Vantuch, M. Malcho, Vplyv množstva $\mathrm{CO} 2$ ako náplne tepelnej trubice, na dobu chladnutia simulátora na získavanie zemského tepla, In: 32 SKMTaT, 38-41 (2013) 